\title{
Thermal Expansion and Elastic Moduli of Electrolyte Materials for High and Intermediate Temperature Solid Oxide Fuel Cell
}

\author{
Peipei Gao ${ }^{1}$, Amy Bolon ${ }^{2}$, Manisha Taneja ${ }^{1}$, Zhilin Xie $^{3}$, Nina Orlovskaya ${ }^{3}$, Miladin Radovic ${ }^{1,2^{*}}$ \\ ${ }^{1}$ Department of Mechanical Engineering, Texas A\&M University, College Station, TX 77843 \\ 2 Department of Materials Science and Engineering, Texas A\&M University, College Station, \\ TX 77843 \\ ${ }^{3}$ Department of Mechanical, Materials and Aerospace Engineering, University of Central \\ Florida, Orlando, FL 32816 \\ * corresponding author: mradovic@ tamu.edu
}

\begin{abstract}
The development of thermal stresses in solid oxide fuel cells (SOFCs), and thus their structural stability and reliability, depends directly on the thermal expansion and elastic moduli of the constituent materials. Therefore, it is important to study these properties of SOFC materials. In this study, the thermal expansion and elastic properties of common electrolyte materials, namely yttria stabilized zirconia (YSZ), scandia and ceria stabilized zirconia (SCSZ) and gadolinia doped ceria (GDC), are reported. High temperature X-ray diffraction (HT-XRD) was used to show that the cubic structure of YSZ and GDC samples is stable throughout the temperature range of $30-800{ }^{\circ} \mathrm{C}$. However, SCSZ undergoes partial cubic to rhombohedral phase transition at around 300 ${ }^{\circ} \mathrm{C}$ but transferred completely back to cubic phase at around $500{ }^{\circ} \mathrm{C}$ upon heating. The coefficient of thermal expansion (CTE) of electrolyte materials was measured using
\end{abstract}


thermo-mechanical analyzer (TMA). It was found that the CTE of SCSZ is almost identical to that of YSZ, but lower than that of GDC. Elastic properties (Young's and shear moduli) were determined in the $25-900{ }^{\circ} \mathrm{C}$ temperature range using resonant ultrasound spectroscopy (RUS). Young's and shear moduli of GDC decrease almost linearly with temperature, with an exception of the small anomaly between $100{ }^{\circ} \mathrm{C}$ and $300{ }^{\circ} \mathrm{C}$. However, the variation of elastic moduli with temperature was found to be highly non-linear for YSZ and SCSZ with minimum values measured at around $600{ }^{\circ} \mathrm{C}$. The deviation from the linear decrease of elastic moduli with increasing temperature is related to the relaxation of oxygen vacancy complexes and phase transformations.

Keywords: anelastic relaxation; ceria; zirconia; phase transformation; 


\section{Introduction}

$\mathrm{ZrO}_{2}$ stabilized with $\mathrm{Y}_{2} \mathrm{O}_{3}$ (YSZ) has been the most important electrolyte material since the inception of solid oxide fuel cells (SOFCs) [1, 2]. Pure $\mathrm{ZrO}_{2}$ shows a monoclinic structure below $1170{ }^{\circ} \mathrm{C}$, tetragonal structure in the temperature range of $1170-2370{ }^{\circ} \mathrm{C}$ and cubic structure above $2370{ }^{\circ} \mathrm{C}$ [3]. The doping of $\mathrm{ZrO}_{2}$ with $\mathrm{Y}_{2} \mathrm{O}_{3}$, where the amount of $\mathrm{Y}_{2} \mathrm{O}_{3}$ usually ranges from $8 \mathrm{~mol} \%$ (8YSZ) to $10 \mathrm{~mol} \%$ (10YSZ), not only generates one mole of oxygen vacancies per mole of dopants, but also stabilizes the high temperature cubic phase (fluorite structure) at room temperature. Below 600 ${ }^{\circ} \mathrm{C}$, oxygen vacancies and dopants tend to form complexes or clusters, such as $\left(\mathrm{Y}_{\mathrm{Zr}}^{\prime} \mathrm{V}_{\mathrm{O}}^{\bullet \bullet}\right)^{\bullet}$ [4-8], $\left(\mathrm{Zr}_{\mathrm{Zr}}^{\mathrm{x}} \mathrm{V}_{\mathrm{O}}^{\bullet \bullet}\right)^{\bullet \bullet}[9-12],\left(2 \mathrm{Y}_{\mathrm{Zr}}^{\prime} \mathrm{V}_{\mathrm{O}}^{\bullet \bullet}\right)^{\mathrm{x}}[8,13]$, and cause local ordering [14-16] that hinders ionic diffusivity in YSZ. However, above $\sim 600{ }^{\circ} \mathrm{C}$, oxygen vacancies become free and disassociate from clusters resulting in high ionic conductivity $[14,17,18]$. Therefore, to ensure the required ionic conductivity of the electrolyte, SOFCs need to be operated at relatively high temperatures $\left(800-1000{ }^{\circ} \mathrm{C}\right)$ where oxygen vacancies are dissociated from the clusters and become highly mobile. The later limits the application of YSZ only to high-temperature SOFCs (HT-SOFCs) [19, 20]. The high operation temperature on the other hand causes the accelerated degradation of materials in SOFCs and high stresses due to thermal expansion mismatch between constituent materials resulting in lower reliability and durability [21-27]. Therefore, intermediate temperature SOFCs (IT-SOFCs) have drawn the attention of researchers and engineers in the recent years [28-32]. 
$10 \mathrm{~mol} \% \mathrm{Sc}_{2} \mathrm{O}_{3}+1 \mathrm{~mol} \% \mathrm{CeO}_{2}$ stabilized $\mathrm{ZrO}_{2}(\mathrm{SCSZ})$ and $\mathrm{Gd}_{\mathrm{x}} \mathrm{Ce}_{1-\mathrm{x}} \mathrm{O}_{2-0.5 \mathrm{x}}(\mathrm{x}$ is between 0.1 and 0.2 ) have been largely studied as potential electrolyte materials for ITSOFC because of their higher ionic conductivities in the $600-800^{\circ} \mathrm{C}$ temperature range when compared to YSZ $[17,30,31]$. For example, it has been reported that SCSZ has the ionic conductivity of $0.084 \mathrm{~S} / \mathrm{cm}$ at $800{ }^{\circ} \mathrm{C}$, which is significantly higher than the conductivity of $0.03 \mathrm{~S} / \mathrm{cm}$ measured in $8 \mathrm{YSZ}$ at the same temperature [33]. However, SCSZ undergoes partial cubic to rhombohedral and back to cubic phase transformations during heating in $300-500{ }^{\circ} \mathrm{C}$ temperature range [34], which consequently brings undesired residual stresses in SOFC stacks.

As to GDC, although it provides much higher ionic conductivity than that of YSZ and SCSZ, it is prone to a partial reduction of $\mathrm{Ce}^{4+}$ to $\mathrm{Ce}^{3+}$ at lower oxygen partial pressure on the anode side, especially at high temperatures (above $600{ }^{\circ} \mathrm{C}$ ) [32]. This reduction in GDC leads to the increased electronic conductivity as well as chemical expansion contributing to the lower cell potentials and reduced efficiency. The chemical expansion of GDC electrolyte also results in the chemical stresses and eventual cracking of GDC electrolyte layers in IT-SOFCs $[30,35,36]$. As a solution, GDC for IT-SOFC were coated with a thin layer of YSZ at the anode side to protect it from the extended reduction $[37,38]$.

On the other hand, mechanical and thermal properties of doped binary oxides, in addition to their transport properties are crucial for durability and reliability of SOFCs. In a previous study, Radovic et al. [39] showed that the elastic modulus and fracture toughness of 8 YSZ shows an obvious nonlinear change vs. temperature with a minimum 
value at around $600{ }^{\circ} \mathrm{C}$, i.e. roughly at the same temperature at which the maximum in anelastic relaxation was observed. Orlovskaya et al. [40] found minimum values of elastic modulus and fracture toughness in SCSZ at approximately $500{ }^{\circ} \mathrm{C}$, which is close to the operation temperature of this electrolyte material in SOFCs. The abnormal changes of mechanical behavior in SCSZ were attributed to the phase transformations from cubic to rhombohedral and then back to cubic in the temperature range of 300 $500{ }^{\circ} \mathrm{C}$. Nowick et al. [13] and Weller et al. [8, 41] observed large mechanical damping peaks (internal friction peaks) in both doped cerias and zirconias below $600{ }^{\circ} \mathrm{C}$. Kushi et al. [42] showed that the drastic drops of elastic moduli occur in the same temperature range where mechanical damping peaks were observed in both YSZ and SCSZ.

A detailed study of the variation of thermo-mechanical properties of common electrolyte materials for HT-SOFCs and IT-SOFCs as a function of temperature are presented in this paper. In the present work, we have investigated the coefficient of thermal expansion in $30-800{ }^{\circ} \mathrm{C} / 900{ }^{\circ} \mathrm{C}$ temperature range using high temperature $\mathrm{X}$ ray diffraction (HT-XRD) and thermomechanical analysis (TMA), and elastic moduli by a high temperature resonant ultrasound spectroscopy (HT-RUS). The results presented in this work are not only important for designing more mechanically and structurally robust SOFCs, but also for a better understanding of mechanisms that lead to the non-linear changes of elastic moduli with temperature in common fast ionic conductors (FICs) having fluorite structure.

\section{Materials and Experimental Methods}


The electrolyte materials used in this study include 8 mol\% $\mathrm{Y}_{2} \mathrm{O}_{3}$ stabilized $\mathrm{ZrO}_{2}$ (8YSZ) and $10 \mathrm{~mol} \% \mathrm{Y}_{2} \mathrm{O}_{3}$ stabilized $\mathrm{ZrO}_{2}$ (10YSZ) as conventional electrolytes for HT-SOFC, as well as $10 \mathrm{~mol} \% \mathrm{Sc}_{2} \mathrm{O}_{3}+1 \mathrm{~mol} \% \mathrm{CeO}_{2}$ stabilized $\mathrm{ZrO}_{2}$ (SCSZ), $\mathrm{Gd}_{0.1} \mathrm{Ce}_{0.9} \mathrm{O}_{0.95}$ (10GDC) and $\mathrm{Gd}_{0.2} \mathrm{Ce}_{0.8} \mathrm{O}_{0.9}$ (20GDC) for IT-SOFC. Commercial 8YSZ (TOSOH Corp., Japan), 10YSZ (TOSOH Corp., Japan), SCSZ (Daiichi Kigenso Kagaku Kogyo Co. Ltd., Japan), 10GDC (Fuel Cell Materials, OH) and 20GDC (Fuel Cell Materials, $\mathrm{OH}$ ) powders were uniaxially cold pressed at $20 \mathrm{MPa}$ for 4 minutes in 12.7 $\mathrm{mm}$ or $25.4 \mathrm{~mm}$ diameter steel die. The green pellets were sintered in ambient air at $1500^{\circ} \mathrm{C}$ for 2 hours with a heating and cooling rate of $5^{\circ} \mathrm{C} / \mathrm{min}$. All examined samples were fabricated in the form of rods or discs. Samples were cut to $4 \times 4 \times 8 \mathrm{~mm}^{3}$ rectangular bars for TMA test and $10 \mathrm{~mm}$ diameter and $2 \mathrm{~mm}$ thick discs for HT-RUS test.

The relative density of all samples was measured to be higher than $97 \%$ after sintering using alcohol immersion method and Archimedes' principle according to ASTM Standard C20-00 [43]. The sintered samples were crushed to powders and characterized with high temperature X-ray diffraction (HT-XRD; X'Pert Pro X-ray Diffraction System, PANalytical, Westborough, MA) with $\mathrm{Cu} \mathrm{K} \alpha$ radiation (wavelength $=0.1542 \mathrm{~nm}$ ) at $45 \mathrm{kV}$ and $40 \mathrm{~mA}$. The two-theta range varied from $20^{\circ}$ to $80^{\circ}$ with a step size of $0.02^{\circ}$ and a step time of $1 \mathrm{~s}$. Heating and cooling rates were 5 ${ }^{\circ} \mathrm{C} /$ min and soaking time at the desired temperature was 20 minutes before scanning. Phase compositions were analyzed utilizing the Inorganic Crystal Structure Database (ICSD) and MDI Jade software. To study the grain size after sintering, samples were 
mechanically polished to a mirror finish using SiC sandpapers with different grits, and then using different size diamond suspensions (from $9 \mu \mathrm{m}$ to $0.1 \mu \mathrm{m}$ ). Well-polished samples went through thermal etching at $1400{ }^{\circ} \mathrm{C}$ for half an hour. The grain size of samples were observed and measured with digital optical microscope (Keyence VHZ100) and field emission scanning electron microscope (FE-SEM; Quanta 600 FEG, FEI, Oregon, USA). Average grain sizes were calculated by measuring the size of over 200 grains.

Coefficients of thermal expansion (CTE) of the examined materials were determined using Q400 series thermomechanical analyzer, TMA (TA Instruments, IL, USA). The $4 \times 4 \times 8 \mathrm{~mm}^{3}$ sample cut from sintered discs was placed between the stage and glass probe. The displacement of the probe that corresponds to the expansion of the sample along longest direction was monitored during heating and cooling. A standard $\mathrm{Al}_{2} \mathrm{O}_{3}$ sample was used to calibrate the equipment before tests. The tests were performed in a standard mode in which the force was held with a constant stress at $0.1 \mathrm{~N}$ during the test. Each sample was subjected to three consecutive heating-cooling thermal cycles. Each thermal cycle included a heating process from the room temperature to $900{ }^{\circ} \mathrm{C}$ with a heating rate of $5{ }^{\circ} \mathrm{C} / \mathrm{min}$, followed by a cooling process to room temperature at a rate of $5^{\circ} \mathrm{C} / \mathrm{min}$, as given by the ASTM E831 standard [44]. The height changes (in $\mu \mathrm{m}$ ) of the sample with temperature during three heating and cooling cycles were monitored and recorded. The weight of the sample was measured before and after every test to ensure that there was no change related to the oxidation or reduction of the sample. 
The Young's and shear moduli of the materials used in the present study were determined using a custom made high-temperature resonant ultrasound spectroscope (HT-RUS) that utilizes commercially available RUS (Magnaflux Quasar, Albuquerque, NM) system. RUS is a high-precision dynamic technique which is used to determine the elastic moduli and energy dissipation (mechanical damping) of the materials by measuring the vibrational spectrum of the samples with well-defined geometry, usually in the shape of parallelepipeds or cylinder $[45,46]$. The details of the experimental setup for resonant ultrasound spectroscopy can be found elsewhere [45, 47, 48]. The sample in the form of a disc was supported by three piezoelectric transducers. One transducer (transmitting transducer) generates an elastic wave of constant amplitude but of varying frequency (covering a large number of vibrational eigenmodes of the sample). The resonance response of the excited sample is detected by the other two transducers (receiving transducers). In order to study the variation of elastic moduli and energy dissipation as a function of temperature, the commercially available setup for RUS at room temperature was further modified for high temperature measurements in which large sapphire or $\mathrm{SiC}$ extension rods were used to transmit ultrasound waves. This arrangement was designed to hold the specimen on the tip of the extension rods, at the desired temperature in the furnace, while keeping the transducers unaffected by high temperature. The sample was heated at a ramping rate of $10{ }^{\circ} \mathrm{C} / \mathrm{min}$ and resonance spectra were collected at an interval of $100{ }^{\circ} \mathrm{C}$ up to $900^{\circ} \mathrm{C}$ after an isothermal hold of 20 minutes. 
Depending on the density and stiffness of the material, measurements were done in the $20-500 \mathrm{kHz}$ frequency range to cover the first 40 eigenfrequencies. The RUS spectra cannot be de-convoluted directly to deduce the elastic constants. Starting from the known sample dimensions, density, and a set of "guessed" elastic constants—namely $\mathrm{C}_{11}$ and $\mathrm{C}_{44}$ for an isotropic solid, the elastic moduli were determined from collected RUS spectra using a multidimensional algorithm (Magnaflux Quasar, Albuquerque, NM) that minimizes the root-mean-square (RMS) error between the measured and calculated resonant peaks. Dissipation energy $\left(\mathrm{Q}^{-1}\right)$ is obtained by the full width at half maximum (FWHM) of the resonant peaks.

\section{Results and Discussion}

\subsection{Structural Characterization}

It is well established by now that the grain size could affect the phase stability and ionic conductivity in doped binary oxides. For example, possible phase transformation could be of concern in the zirconia-based fluorite solid ionic conductors since fluorite structure is a metastable structure at low temperatures. Zevalkink et al. [49] showed that SCSZ goes through phase transformations from cubic to rhombohedral at around $300{ }^{\circ} \mathrm{C}$, and then back to cubic at around $500{ }^{\circ} \mathrm{C}$. More recently, Yarmolenko et al. [34] observed that the grain size of SCSZ influences the fraction of transformed rhombohedral phase. As it was discussed before by many researchers [50-52], the transport properties of GDC and YSZ also largely depends on grain sizes. 
To eliminate the possible influence of different grain sizes on thermal properties, elastic properties and phase compositions, all samples of different materials in this study were processed targeting comparable grain sizes. SEM (Figure 1a, 1c, 1e) and optical microscopy (Figure 1b, 1d, 1f) were used to determine the grain sizes in well-polished samples after thermal etching. The average grain sizes of 8YSZ, 10YSZ, SCSZ, 10GDC, and 20GDC and were found to be $4.9 \pm 1.6 \mu \mathrm{m}, 5.0 \pm 1.6 \mu \mathrm{m}, 4.8 \pm 1.4 \mu \mathrm{m}, 5.2 \pm 1.5 \mu \mathrm{m}$, and $5.2 \pm 1.5 \mu \mathrm{m}$, respectively, Table 1 . In other words, grain sizes in all samples were comparable and around $5 \mu \mathrm{m}$.

Figure 2 shows diffraction patterns for 8YSZ, SCSZ and 20GDC. 8YSZ (Figure 2a) and 20GDC (Figure 2d) XRD patterns from room temperature to $800{ }^{\circ} \mathrm{C}$ indicate that only fluorite structure is present in both samples during heating. However, in SCSZ, a partial phase transformation from cubic to rhombohedral and back to cubic was observed in the temperature range of $300-500{ }^{\circ} \mathrm{C}$ during heating (Figure $2 \mathrm{~b}$ and $2 \mathrm{c}$ ). The results of XRD with smaller temperature steps in Figure 2c show that the rhombohedral peaks appear in SCSZ around $300^{\circ} \mathrm{C}$, and then it gradually disappears until $500{ }^{\circ} \mathrm{C}$. The lattice parameters of 8YSZ, 10YSZ, SCSZ, 10GDC and 20GDC increase almost linearly with the temperature as shown in Figure 3. The figure also shows that the lattice parameter values remain unchanged after a heating-cooling cycle as compared to the room temperature lattice parameters of as processed samples. Thermal expansion coefficient from 30 to $800{ }^{\circ} \mathrm{C}$ calculated from HT-XRD results (Table 1) are $10.5 \times 10^{-6} /{ }^{\circ} \mathrm{C}, 10.6 \mathrm{x}$ $10^{-6} /{ }^{\circ} \mathrm{C}, 10.3 \times 10^{-6} /{ }^{\circ} \mathrm{C}, 12.0 \times 10^{-6} /{ }^{\circ} \mathrm{C}$ and $12.2 \times 10^{-6} /{ }^{\circ} \mathrm{C}$ for 8YSZ, 10YSZ, SCSZ, 10GDC and 20GDC, respectively. Note here that the lattice parameter changes with 
temperature presented for SCSZ in Figure 3 and the corresponding coefficients of thermal expansions reported above are only for the cubic (fluorite) phase in SCSZ.

\subsection{Thermal Expansion}

Figure 4 shows results obtained from thermomechanical analysis (TMA) of 8YSZ, 10YSZ, SCSZ, 10GDC and 20GDC samples. Thermal expansion $\left(\Delta \mathrm{L} / \mathrm{L}_{0}\right)$ vs. temperature plots in Figure $4 \mathrm{a}, 4 \mathrm{c}$ and $4 \mathrm{e}$ show almost a linear increase of $\Delta \mathrm{L} / \mathrm{L}_{0}$ with temperature in the $30-900{ }^{\circ} \mathrm{C}$ temperature range, with a similar trend to that observed in the case of lattice parameter changes in Figure 3. All samples were tested in three heating-cooling cycles and since the overlaps between curves obtained in all heatingcooling cycles were good, only results from the first heating and cooling cycle are presented for each material. The slopes of the straight lines fitting of data in Figure 4a, $4 \mathrm{c}$ and $4 \mathrm{e}$ give the average coefficients of thermal expansion (CTE) of $10.3 \times 10^{-6} /{ }^{\circ} \mathrm{C}$, $10.4 \times 10^{-6} /{ }^{\circ} \mathrm{C}, 10.5 \times 10^{-6} /{ }^{\circ} \mathrm{C}, 12.1 \times 10^{-6} /{ }^{\circ} \mathrm{C}$, and $12.2 \times 10^{-6} /{ }^{\circ} \mathrm{C}$ for $8 \mathrm{YSZ}, 10 \mathrm{YSZ}$, SCSZ, 10GDC and 20GDC, respectively, Table 1. It is worth pointing out that the CTE of GDCs is higher than that of examined YSZs and SCSZ. Those values are in good agreement with coefficients of thermal expansion determined using HT-XRD results, as it is shown in Table 1. The results from three heating and cooling cycles are in excellent agreement with the CTE values reported elsewhere for YSZ [53-56], SCSZ [57] and GDC $[58,59]$.

Instantaneous thermal expansions at any temperature in the $30-900{ }^{\circ} \mathrm{C}$ temperature range was also calculated from the thermal expansion vs. temperature 
curves as CTE $=\frac{1}{\mathrm{~L}_{0}} \frac{\mathrm{dL}}{\mathrm{dT}}$, where, $\mathrm{L}_{0}, \mathrm{~L}$ and $\mathrm{T}$ are the original length of sample at room temperature, length and temperature, respectively. Therefore, the instantaneous CTE was determined as a slope of the tangent on thermal expansion vs. temperature curve at each particular temperature. Figure $4 \mathrm{~b}, 4 \mathrm{~d}$ and $4 \mathrm{f}$ show the average value of instantaneous CTEs from three heating and cooling cycles. The magnitudes of instantaneous CTEs increase slightly with increasing temperature for all examined samples.

Instantaneous CTE vs. temperature plots for 8 YSZ and 10YSZ in Figure 4b clearly show a monotonic increase of CTE with increasing temperature. The saddle point at around $600{ }^{\circ} \mathrm{C}$ followed by the increasing slope of instantaneous CTE vs. temperature curve may be attributed to an order-disorder transition in 8YSZ. Previous neutron diffraction results suggested that the order-disorder transition is a result of the dissociation of vacancy-cation complexes or clusters in $8 \mathrm{~mol} \%$ YSZ in the $600-700{ }^{\circ} \mathrm{C}$ temperature range could result in the slight change of the slope of the lattice parameter vs. temperature curve around that temperature [60].

The change of instantaneous CTE with increasing temperature in SCSZ (Figure 4d) is similar to that in YSZ. However, the obvious change of the slope at around $500{ }^{\circ} \mathrm{C}$ in SCSZ may be attributed to the phase transformations. As shown in the XRD results (Figure 2b and Figure 2c), complex phase transformations take place in SCSZ between $300{ }^{\circ} \mathrm{C}$ and $500{ }^{\circ} \mathrm{C}$. Yarmolenko et al. [57] has shown that the cubic phase SCSZ (10.6 x $\left.10^{-6}{ }^{\circ} \mathrm{C}^{-1}\right)$ has significantly higher CTE than rhombohedral phase $\left(8.6 \times 10^{-6}{ }^{\circ} \mathrm{C}^{-1}\right)$. This may contribute to the relative slower slope increase in the temperature below $500{ }^{\circ} \mathrm{C}$ and 
the sudden increase of instantaneous slope at the temperature around $500{ }^{\circ} \mathrm{C}$ observed in Figure 4d. As in the case of YSZ, the increase in the slope of instantaneous CTE vs. temperature curve above $600{ }^{\circ} \mathrm{C}$ in SCSZ may also be attributed to the order-disorder transition. Although more work is needed to fully understand the underlying mechanisms for the observed changes in instantaneous CTE with temperature in SCSZ, we can conclude at this point that those changes should be most likely associated with the local ordering of defect complexes and phase transformations.

In the case of GDC, a noticeable increase in the instantaneous CTE above $600^{\circ} \mathrm{C}$ in Figure 4f coincides more with the onset of intensive oxygen vacancy formation and corresponding chemical expansion in GDC [30, 35, 59]. Although the increase of oxygen vacancies leads to the contraction of lattice, the loss of oxygen atoms lead to the reduction of $\mathrm{Ce}^{4+}$ (ionic radius: $0.97 \AA$ ) to $\mathrm{Ce}^{3+}$ (ionic radius: $1.143 \AA$ ), which can also largely contribute to the increase of instantaneous CTE together with the order-disorder transition [61].

\subsection{Elastic Moduli}

The results of RUS in the $25-900{ }^{\circ} \mathrm{C}$ temperature range for YSZ, SCSZ and GDC are summarized in Figures 5-8. Before discussing the changes of Young's and shear moduli with temperature in those typical electrolyte materials, it is worth mentioning that resonant spectra obtained by RUS show some interesting anomalies. For example, selected but typical resonant peaks for 20GDC (Figure 5a) and 8YSZ (Figure 5b), show not only a shift of resonant peaks to the lower frequencies with increasing 
temperature (labeled with green dash lines in Figure 5) as the result of a decrease in elastic moduli, but also their broadening and significant decrease in their intensity in certain temperature ranges. However, other typical oxides, such as $\mathrm{Al}_{2} \mathrm{O}_{3}$ shown in Figure $5 \mathrm{c}$ do not show any significant broadening of resonant peaks in the entire temperature range. The broadening of the resonant peak is observed in doped cerias and zirconias in the $100-400{ }^{\circ} \mathrm{C}$ and $300-700{ }^{\circ} \mathrm{C}$ temperature ranges, respectively. As the FWHM of the resonant peaks represent ultrasonic attenuation, the broadening of the resonant peaks can be attributed to the increase in the attenuation of ultrasonic waves (or mechanical loss). The latter also indicates that the energy of the ultrasonic waves is dissipated more in a certain temperature ranges in examined doped binary oxides.

Figures 6 shows the change of Young's and shear moduli with temperature for 8YSZ, 10YSZ, SCSZ, 10GDC and 20GDC. For comparison, the elastic moduli of $\mathrm{Al}_{2} \mathrm{O}_{3}$ are also plotted as a function of temperature in Figure 6. While the Young's and shear moduli of $\mathrm{Al}_{2} \mathrm{O}_{3}$ decrease linearly with increasing temperature, their change with temperature deviates from the linear trend for all examined electrolyte materials. 10GDC and 20GDC show slight deviation from the linear decrease of elastic moduli with temperatures between $100^{\circ} \mathrm{C}$ and $400^{\circ} \mathrm{C}$ (Figure 6). The changes of elastic moduli of 8YSZ, 10YSZ and SCSZ with temperature deviate even more from the linear trend with the minimum values of elastic moduli at around $600{ }^{\circ} \mathrm{C}$. Above $600{ }^{\circ} \mathrm{C}$, the elastic moduli were even found to increase slightly with increasing temperature in all doped zirconias. The drop in elastic moduli is quite significant from room temperature to approximately $600{ }^{\circ} \mathrm{C}$, i.e. it is $32.3 \%, 20.5 \%$ and $40.0 \%$ in 8YSZ, 10 YSZ and SCSZ, 
respectively. Figure 7 compares normalized Young's moduli (i.e. Young's moduli at any temperature divided by Young's moduli at room temperature) that were obtained in this study using RUS for 8YSZ, 10YSZ and SCSZ to normalized storage moduli measured using dynamic mechanical analysis (DMA) [62]. Although the changes of normalized moduli with temperature in Figure 7 were determined using two different dynamic methods, they show quite similar trends. However, the minimum values of elastic moduli determined by RUS are shifted towards higher temperatures when compared to the results from DMA. The reason for the observed shift of elastic modulus minima to higher temperatures in RUS lies in the fact that this drop in elastic moduli is frequency dependent, i.e. it appears at higher temperatures as the measurements were carried out at higher frequencies, as it is discussed in more details elsewhere [62]. The RUS measurements in this study were performed in the $20-500 \mathrm{kHz}$ range, which is significantly higher than the frequency range of $0.1-100 \mathrm{~Hz}$ that was used in the DMA tests [62].

Figure 8 shows mechanical loss $\left(\mathrm{Q}^{-1}\right.$ or tan $\left.\delta\right)$ obtained from the FWHM of resonant peaks (such as those in Figure 5). RUS allows not only a simultaneous measurement of more than one elastic constant but also the determination of ultrasonic attenuation $\left(\mathrm{Q}^{-1}\right)$ as a direct manifestation of irreversible energy absorption by various physical processes. $\mathrm{Q}^{-1}$ can be determined from the RUS spectra assuming: $\mathrm{Q}^{-1}{ }_{\mathrm{k}}=$ $\Delta \omega_{\mathrm{k}} / \omega_{\mathrm{ko}}$, where $\omega_{\mathrm{ko}}$ is the frequency associated with $\mathrm{k}_{\mathrm{th}}$ eigenmode, and $\Delta \omega_{\mathrm{k}}$ is the FWHM of that mode. Large mechanical damping peaks appear in the $25-300{ }^{\circ} \mathrm{C}$ temperature range for $10 \mathrm{GDC}$ and $20 \mathrm{GDC}, 200-700{ }^{\circ} \mathrm{C}$ for $8 \mathrm{YSZ}, 200-600{ }^{\circ} \mathrm{C}$ for 
10YSZ and $200-700{ }^{\circ} \mathrm{C}$ for SCSZ, i.e. in the same temperature range in which a noticeable deviation from the linear decrease of elastic modulus with temperature was observed (Figure 6). This suggests that the drop in elastic moduli and increase in mechanical damping are linked phenomena affected by the same physical mechanism(s). In addition, stabilized zirconias show much larger mechanical loss peaks than doped cerias, and consequently a much higher drop in elastic moduli with temperature. It is worth noting that mechanical damping peaks for $8 \mathrm{YSZ}$ are larger than that of 10YSZ, but smaller than SCSZ. The similar damping peaks were obtained using DMA in 8YSZ, 10YSZ and SCSZ [62], but with maximum values at significantly lower temperatures (approximately $200{ }^{\circ} \mathrm{C}$ lower) than those reported here, because those tests were carried out at much lower frequencies. To further elucidate the possible mechanisms that result in this unusual changes of elastic moduli and high mechanical damping in 8YSZ and 10YSZ, the results in Figure 5-8 were further analyzed and compared to the results obtained using DMA [62].

Previous studies have shown that the elastic moduli of single crystal and polycrystalline zirconia doped with yttria [42, 63, 64], scandia [42], and calcia [65] nonlinearly decrease with temperature with a significant drop in moduli at temperatures that corresponds to the maximum of mechanical damping (i.e. mechanical loss or internal friction) which can be expressed as $\mathrm{Q}^{-1} \approx \tan \delta=\mathrm{E}^{\prime \prime} / \mathrm{E}^{\prime}$, where $\delta$ is loss angle, and $\mathrm{E}^{\prime}$ and $E^{\prime \prime}$ are the real and imaginary part of elastic modulus, respectively. As it was discussed previously [62], the drop of elastic moduli as well as the peaks in the mechanical loss $\left(\mathrm{Q}^{-1}\right)$ spectra can be attributed to the anelastic relaxation of elastic (and 
dielectric) dipoles by the hopping of the oxygen vacancy around the cation and/or local ordering of oxygen vacancies. At lower temperatures, mechanical loss is most likely associated with the anelastic relaxation of simple dipoles such as $\left(\mathrm{Y}_{\mathrm{Zr}}^{\prime} \mathrm{V}_{\mathrm{O}}^{\bullet \bullet}\right)^{\bullet}$, while with higher dopant concentrations it may be caused also by the anelastic relaxation of more complex clusters such as $\left(2 \mathrm{Y}_{\mathrm{Zr}}^{\prime} \mathrm{V}_{\mathrm{O}}^{\bullet \bullet}\right)^{\mathrm{x}}[8,63]$, and/or local ordering of oxygen vacancies $[14,66]$.

A phase transformation(s) was also proposed in some studies [42, 67, 68] as another possible mechanism that can lead to the non-linear change of elastic moduli and observed mechanical damping peaks. As it is discussed by Navrotsky [15], the cubic structure has a large possibility to transform to a locally fluorite-derivative structure (delta phase) or other similar structures (pyrochlore, bixbyite, zirconolite) in some doped binary oxides. However, our high temperature XRD results showed that the cubic crystal structure is stable in 8YSZ (Figure 2a) and 10YSZ (not shown here) in the entire temperature range. Gibson et al. [60] also did not observe any first order phase transformations in $8 \mathrm{YSZ}$ using neutron diffraction between 150 and $1000{ }^{\circ} \mathrm{C}$, while Cai et al. [69] reported that cubic structure is entirely stable in 10YSZ in the temperature ranges of $-233-1197{ }^{\circ} \mathrm{C}$ tested using high temperature Raman spectroscopy. Finally, the absence of any abrupt changes in the coefficients of thermal expansion and the fact that the temperature at which maximum attenuation occurs is frequency dependent almost exclusively rules out any long-range first order phase transformations in YSZ samples. 
Similar to YSZ, the anelastic relaxation of dipoles such as $\left(\mathrm{Sc}_{\mathrm{Zr}}^{\prime} \mathrm{V}_{\mathrm{O}}^{\bullet \bullet}\right)^{\bullet}$ and $\left(2 \mathrm{Sc}_{\mathrm{Zr}}^{\prime} \mathrm{V}_{\mathrm{O}}^{\bullet \bullet}\right)^{\mathrm{x}}$, and possibly local ordering of oxygen vacancies may also be responsible for the intense decrease of elastic moduli and the increase of mechanical damping that was observed in SCSZ. However, unlike in YSZ, two phase transformations in SCSZ were detected between $300{ }^{\circ} \mathrm{C}$ and $500{ }^{\circ} \mathrm{C}$ by high temperature XRD in this (Figure $2 \mathrm{~b}$ and 2c) and several other studies [28, 34]. In addition, the phase transformations could be assisted by external applied stress or residual stress [70]. The drop in elastic moduli is more significant and mechanical damping is larger (Figure 8) in SCSZ than in YSZ between $300{ }^{\circ} \mathrm{C}$ and $500{ }^{\circ} \mathrm{C}$ suggesting that those phase transformations in SCSZ might have a huge influence on its elastic moduli and mechanical damping.

The room temperature Young's modulus of 10GDC (2.1\% Porosity - 204 GPa) and 20GDC (2.7 \% Porosity-202 GPa) used in the present study are slightly lower than those reported in literature $(212 \mathrm{GPa}$ ) for almost fully dense samples [71]. Unlike in the case of YSZ and SCSZ, the elastic moduli of 10GDC and 20GDC decrease almost linearly with temperature, with only slight deviation from the linear trend between 100 ${ }^{\circ} \mathrm{C}$ and $400{ }^{\circ} \mathrm{C}$. However, as in the case of doped zirconias, an increase in mechanical damping was also observed, although the magnitude of the mechanical damping was significantly lower in GDCs than in doped zirconias. As it was proposed earlier by Nowick and his collaborators $[13,72]$ who carried out the torsional pendulum studies of several doped cerias, mechanical damping in this temperature range can be also attributed to the anelastic relaxation of elastic dipoles such as $\left(\mathrm{Gd}_{\mathrm{Ce}}^{\prime} \mathrm{V}_{\mathrm{O}}^{\bullet \bullet}\right)^{\bullet}$ and $\left(2 \mathrm{Gd}_{\mathrm{Ce}}^{\prime} \mathrm{V}_{\mathrm{O}}^{\bullet \bullet}\right)^{\mathrm{x}}$. The low magnitude of mechanical damping and temperature range in 
GDCs is not surprising if we take into account the results of previous experimental and computational studies $[8,30,72-74]$ that clearly show that the association energies of oxygen vacancy-dopants are much lower in GDCs than YSZs, which in turn also contribute to the superb ionic conductivity of GDCs at much lower temperatures when compared to YSZs. Consequently, the deviation from the linear change of elastic moduli with temperature and mechanical damping peak appear at approximately $100{ }^{\circ} \mathrm{C}$ higher temperatures in 20GDC than in 10GDC since more complex clusters, such as $\left(2 \mathrm{Gd}_{\mathrm{Ce}}^{\prime} \mathrm{V}_{\mathrm{O}}^{\bullet \bullet}\right)^{\mathrm{x}}$ dipoles, and/or more local orderings are formed in the former with a higher association energy $[41,72]$.

\section{Conclusions}

In the present work, we report on the changes of coefficients of thermal expansion and elastic moduli in the $30-900{ }^{\circ} \mathrm{C}$ temperature range for $8 \mathrm{~mol} \% \mathrm{Y}_{2} \mathrm{O}_{3}$ stabilized $\mathrm{ZrO}_{2}$ (8YSZ) and $10 \mathrm{~mol} \% \mathrm{Y}_{2} \mathrm{O}_{3}$ stabilized $\mathrm{ZrO}_{2}$ (10YSZ) as conventional electrolytes for high temperature SOFC, as well as $10 \mathrm{~mol}_{2} \mathrm{Sc}_{2} \mathrm{O}_{3}, 1 \mathrm{~mol} \% \mathrm{CeO}_{2}$ stabilized $\mathrm{ZrO}_{2}$ (SCSZ), $\mathrm{Gd}_{0.1} \mathrm{Ce}_{0.9} \mathrm{O}_{1.95}$ (10GDC) and $\mathrm{Gd}_{0.2} \mathrm{Ce}_{0.8} \mathrm{O}_{1.9}$ (20GDC) for intermediate temperature SOFC, all having the microstructure consisting of the $\sim 5 \mu \mathrm{m}$ grains. It was found that fluorite structure was stable from $30{ }^{\circ} \mathrm{C}$ to $800{ }^{\circ} \mathrm{C}$ in $8 \mathrm{YSZ}$, 10YSZ, 10GDC and 20GDC using high temperature X-ray diffraction. In SCSZ, a partial phase transformation from cubic to rhombohedral, and then back to cubic were observed in the temperature range of $300-500{ }^{\circ} \mathrm{C}$. 
The thermal expansion of the examined electrolyte materials was determined using high temperature XRD and TMA, while Young's (E) and shear moduli (G) as well as ultrasonic attenuation $\left(\mathrm{Q}^{-1}\right)$ were determined using RUS. The coefficient of thermal expansion (CTE) of SCSZ was found to be almost identical to that of YSZ, but lower than that of GDC. The deviations in CTE changes with temperature at around $600{ }^{\circ} \mathrm{C}$ could be an indication of order-disorder transitions in these electrolyte materials, i.e. 8YSZ, 10YSZ, SCSZ, 10GDC and 20GDC. In addition, phase transformations, which take place between $300^{\circ} \mathrm{C}$ and $500{ }^{\circ} \mathrm{C}$ in SCSZ, might have effect on its CTE. A large increase in the instantaneous CTE of GDC above $600{ }^{\circ} \mathrm{C}$ is most likely the results of chemical expansion.

The variation of elastic moduli with temperature was found to be highly nonlinear for YSZs and SCSZ with the minimum magnitudes of Young's and shear moduli at about $600{ }^{\circ} \mathrm{C}$. It was found that for those stabilized zirconias, the temperature showing the minimum value of elastic moduli vs. temperature curves corresponds to the temperature of maximum mechanical loss due to phase transformations in SCSZ, the most likely anelastic relaxation of dipoles and probably the local ordering of oxygen vacancies. However, in GDCs where activation energies for the reorientation of vacancy-dopant complexes is much lower than in YSZ and SCSZ, the deviations from the linearity of elastic moduli with temperature appear at much lower temperatures (200 - $400{ }^{\circ} \mathrm{C}$ ) with smaller mechanical loss peaks, when compared to doped zirconia ceramics. 


\section{AKNOWLAGEMNT}

This work was supported by the U.S. National Science Foundation (CAREER Award number DMR-1057155). Authors are also grateful to Dr. Edgar Lara-Curzio and Dr. Robbie Peascoe, Oak Ridge National Laboratory, for help with high-temperature X-ray diffraction.

\section{Tables}

Table 1. Grain sizes and coefficients of thermal expansions obtained from XRD and TMA results for different SOFC electrolyte materials.

\begin{tabular}{|c|c|c|c|}
\hline \multirow{2}{*}{ Sample } & Grain size & $\begin{array}{c}\text { CTE from XRD } \\
\left(30 \text { to } 800{ }^{\circ} \mathrm{C}\right)\end{array}$ & $\begin{array}{c}\text { Average CTE form TMA } \\
\left(30 \text { to } 900{ }^{\circ} \mathrm{C}\right)\end{array}$ \\
\cline { 2 - 4 } & $\mu \mathrm{m}$ & $/{ }^{\circ} \mathrm{C}$ & $1{ }^{\circ} \mathrm{C}$ \\
\hline $8 \mathrm{YSZ}$ & $4.9 \pm 1.6$ & $10.5 \times 10^{-6}$ & $10.3 \times 10^{-6}$ \\
\hline $10 \mathrm{YSZ}$ & $5.0 \pm 1.6$ & $10.6 \times 10^{-6}$ & $10.4 \times 10^{-6}$ \\
\hline SCSZ* & $4.8 \pm 1.4$ & $10.3 \times 10^{-6}$ & $12.1 \times 10^{-6}$ \\
\hline 10GDC & $5.2 \pm 1.5$ & $12.0 \times 10^{-6}$ & $12.2 \times 10^{-6}$ \\
\hline 20GDC & $5.2 \pm 1.5$ & $12.2 \times 10^{-6}$ & 10.5 \\
\hline
\end{tabular}

*only for cubic phase

\section{Figure captions:}

Table 1. Grain sizes and coefficients of thermal expansions obtained from XRD and TMA results for different SOFC electrolyte materials

Figure 1. The SEM images of (a) 8YSZ, (c) SCSZ, (e) 20GDC and the optical microscopy images of (b) 8YSZ, (d) SCSZ, (f) 20GDC after thermal etching.

Figure 2. The high temperature XRD results of (a) 8YSZ, (b) SCSZ, (c) SCSZ magnified in $28^{\circ}-32^{\circ} 2 \theta$ range and (d) 20GDC. 
Figure 3. The lattice parameter changes of 8YSZ, 10YSZ, SCSZ, 10GDC and 20GDC vs. temperature. The open symbols represent lattice parameters at $30^{\circ} \mathrm{C}$ obtained after heating process.

Figure 4. The thermal expansion vs. temperature of (a) 8YSZ and 10YSZ, (c) SCSZ, (e) 10GDC and 20GDC, and instantaneous CTE vs. temperature plots for (b) 8 YSZ and 10YSZ, (d) SCSZ, (f) 10GDC and 20GDC. Error bars in (b), (d) and (f) represent standard deviations from measurements in three heating and three cooling cycles.

Figure 5. The typical but selected RUS resonant peaks at different temperatures for (a) 20GDC, (b) $8 \mathrm{YSZ}$ and (c) $\mathrm{Al}_{2} \mathrm{O}_{3}$.

Figure 6. (a) The Young's modulus and (b) shear modulus of $\mathrm{Al}_{2} \mathrm{O}_{3}, 8 \mathrm{YSZ}, 10 \mathrm{YSZ}$, SCSZ, 10GDC and 20GDC determined by RUS.

Figure 7. The comparison of the normalized Young's modulus of 8YSZ, 10YSZ and SCSZ obtained by RUS and DMA.

Figure 8. The comparison of mechanical damping in 8YSZ, 10YSZ, 10GDC and 20GDC by RUS. The mechanical damping of $\mathrm{Al}_{2} \mathrm{O}_{3}$ is also shown for comparison. 


\section{REFERENCES}

[1] S. Singhal, S.C. Singhal, K. Kendall, High-temperature Solid Oxide Fuel Cells:

Fundamentals, Design and Applications: Fundamentals, Design and Applications, Elsevier Science (2003).

[2] P. Knauth, H.L. Tuller, J. Am. Ceram. Soc. 85 (2002) 1654.

[3] R. Stevens, L. Magnesium Elektron, An Introduction to Zirconia, Magnesium Elektron Limited (1983).

[4] H. Morikawa, Y. Shimizugawa, F. Marumo, T. Harasawa, H. Ikawa, K. Tohji, Y. Udagawa, J. Ceram. Soc. Jpn. 96 (1988) (1111) 253.

[5] M.H. Tuilier, J. Dexpert-Ghys, H. Dexpert, P. Lagarde, J. Solid State Chem. 69 (1987) (1) 153.

[6] L. Xiaoyun, B. Hafskjold, J. Phys.: Condens. Matter 7 (1995) (7) 1255.

[7] M. Ohta, K. Kirimoto, K. Nobugai, J.K. Wigmore, T. Miyasato, Jpn. J. Appl. Phys. 40 (2001) 5377.

[8] M. Weller, B. Damson, A. Lakki, J Alloy Compd 310 (2001) 47.

[9] P. Li, I.W. Chen, J.E. Penner-Hahn, Phys Rev B 48 (1993) (14) 10074.

[10] M. Cole, C.R.A. Catlow, J.P. Dragun, J. Phys. Chem. Solids 51 (1990) (6) 507.

[11] C.R.A. Catlow, A.V. Chadwick, G.N. Greaves, L.M. Moroney, J. Am. Ceram. Soc. 69 (1986) (3) 272.

[12] F. Shimojo, T. Okabe, F. Tachibana, M. Kobayashi, H. Okazaki, J. Phys. Soc. Jpn. 61 (1992) (8) 2848.

[13] A.S. Nowick, B.S. Berry, Anelastic relaxation in crystalline solids Academic press, New York (1972).

[14] J. Kondoh, S. Kikuchi, Y. Tomii, Y. Ito, J. Electrochem. Soc. 145 (1998) (5) 1550.

[15] A. Navrotsky, J. Mater. Chem. 20 (2010) (47) 10577.

[16] J.P. Goff, W. Hayes, S. Hull, M.T. Hutchings, K.N. Clausen, Phys Rev B 59 (1999) (22) 14202.

[17] Y. Arachi, H. Sakai, O. Yamamoto, Y. Takeda, N. Imanishai, Solid State Ionics 121 (1999) (1-4) 133.

[18] S. Komine, F. Munakata, J Mater Sci 40 (2005) (15) 3887.

[19] J.W. Fergus, J. Power Sources 162 (2006) (1) 30.

[20] L.J. Gauckler, D. Beckel, B.E. Buergler, E. Jud, U.P. Muecke, M. Prestat, J.L.M. Rupp, J. Richter, CHIMIA International Journal for Chemistry 58 (2004) (12) 837.

[21] J.P.P. Huijsmans, F.P.F. van Berkel, G.M. Christie, J. Power Sources 71 (1998) (1-2) 107.

[22] N.Q. Minh, Centenary of Nernst' s Discovery of Zirconia Electrolytes - Review of Zirconia-Based Electrochemical Technologies, International symposium; 6th, Solid oxide fuel cells, Electrochemical Society, Honolulu, HI (1999), p.127-134.

[23] K. Kanamura, S. Yoshioka, Z.-i. Takehara, Bull. Chem. Soc. Jpn. 65 (1992) (2) 309.

[24] A. Nakajo, C. Stiller, G. Härkegård, O. Bolland, J. Power Sources 158 (2006) (1) 287.

[25] L.-K. Chiang, H.-C. Liu, Y.-H. Shiu, C.-H. Lee, R.-Y. Lee, Renewable Energy 33 (2008) (12) 2580 .

[26] C.-K. Lin, T.-T. Chen, Y.-P. Chyou, L.-K. Chiang, J. Power Sources 164 (2007) (1) 238.

[27] A. Selimovic, M. Kemm, T. Torisson, M. Assadi, J. Power Sources 145 (2005) (2) 463.

[28] Z. Wang, M. Cheng, Z. Bi, Y. Dong, H. Zhang, J. Zhang, Z. Feng, C. Li, Mater. Lett. 59 (2005) (19-20) 2579. 
[29] D.S. Lee, W.S. Kim, S.H. Choi, J. Kim, H.W. Lee, J.H. Lee, Solid State Ionics 176 (2005) (1-2) 33.

[30] M. Mogensen, N.M. Sammes, G.A. Tompsett, Solid State Ionics 129 (2000) (1-4) 63.

[31] B.C.H. Steele, Solid State Ionics 129 (2000) (1-4) 95.

[32] M. Gödickemeier, L.J. Gauckler, J. Electrochem. Soc. 145 (1998) (2) 414.

[33] O. Yamamoto, Electrochim Acta 45 (2000) (15-16) 2423.

[34] Sergey Yarmolenko, Jag Sankar, Nicholas Bernier, Michael Klimov, Jay Kapat, N. Orlovskaya, J. Fuel Cell Sci. Technol. 6 (2009) 8.

[35] S.R. Bishop, H.L. Tuller, Y. Kuru, B. Yildiz, J. Eur. Ceram. Soc. 31 (2011) (13) 2351.

[36] Y. Kuru, S.R. Bishop, J.-J. Kim, B. Yildiz, H.L. Tuller, ECS Trans. 35 (2011) (1) 1131.

[37] F.M.B. Marques, L.M. Navarro, Solid State Ionics 90 (1996) (1-4) 183.

[38] A. Tsoga, A. Gupta, A. Naoumidis, P. Nikolopoulos, Acta Mater. 48 (2000) (18-19) 4709.

[39] M. Radovic, E. Lara-Curzio, R. Trejo, B. Armstrong, C. Walls, Elastic Properties, Equibiaxial Strength and Fracture Toughness of 8mol\% YSZ Electrolyte for SOFC, In: H. Lin, W. Kriven, Editors, $28^{\text {th }}$ Cocoa Beach Conference on Advanced Ceramics and Composites Ceramics, The American Ceramic Society (2003).

[40] N. Orlovskaya, S. Lukich, G. Subhash, T. Graule, J. Kublert, J. Power Sources 195 (2010) (9) 2774.

[41] M. Weller, A. Lakki, Ber Bunsen Phys Chem 101 (1997) (9) 1297.

[42] T. Kushi, K. Sato, A. Unemoto, S. Hashimoto, K. Amezawa, T. Kawada, J. Power Sources 196 (2011) (19) 7989.

[43] ASTM standard C20-00, ASTM International (2005).

[44] ASTM Standard E83, Standard Test Method for Linear Thermal Expansion of Solid Materials by Thermomechanical Analysis ASTM International (2009).

[45] M. Radovic, E. Lara-Curzio, L. Rieser, Mater. Sci. Eng., A 368 (2004) 56.

[46] A. Migliori, J.L. Sarrao, Resonant Ultrasound Spectroscopy: Applications to Physics, Materials Measurements and Nondestructive Evaluation, John Wiley and Sons, New York (1997).

[47] M. Radovic, M.W. Barsoum, A. Ganguly, T. Zhen, P. Finkel, S.R. Kalidindi, E. LaraCurzio, Acta Mater. 54 (2006) 2757.

[48] M. Radovic, E. Lara-Curzio, Acta Mater. 52 (2004) (20) 5747.

[49] A. Zevalkink, A. Hunter, M. Swanson, C. Johnson, J. Kapat, N. Orlovskaya, Processing and Characterization of $\mathrm{Sc} 2 \mathrm{O} 3-\mathrm{CeO} 2-\mathrm{ZrO} 2$ Electrolyte Based Intermediate Temperature Solid Oxide Fuel Cells, In: T. Armstrong, C. Masquelier, Y. Sadaoka, E. Traversa, Editors, 2006 Materials Research Society Fall Meeting (2007).

[50] A. Hara, Y. Hirata, S. Sameshima, N. Matsunaga, T. Horita, J. Ceram. Soc. Jpn. 116 (2008) (1350) 291.

[51] G.M. Christie, F.P.F. van Berkel, Solid State Ionics 83 (1996) (1-2) 17.

[52] C. Peters, A. Weber, B. Butz, D. Gerthsen, E. Ivers-Tiffée, J. Am. Ceram. Soc. 92 (2009) (9) 2017.

[53] N.M. Sammes, Y. Du, Int. J. Appl. Ceram. Technol. 4 (2007) (2) 89.

[54] H. Chen, X. Zhou, C. Ding, J. Eur. Ceram. Soc. 23 (2003) (9) 1449.

[55] M. Mori, T. Yamamoto, H. Itoh, H. Inaba, H. Tagawa, Journal of the Electrochemical Society 145 (1998) 1374.

[56] H. Hayashi, T. Saitou, N. Maruyama, H. Inaba, K. Kawamura, M. Mori, Solid State Ionics 176 (2005) (5-6) 613.

[57] D. Yarmolenko, D. Ray, J. Pai, Sankar, Volume 3: Design and Manufacturing (2007) 305. 
[58] H. Hayashi, M. Kanoh, C.J. Quan, H. Inaba, S. Wang, M. Dokiya, H. Tagawa, Solid State Ionics 132 (2000) (3-4) 227.

[59] S. Wang, M. Katsuki, T. Hashimoto, M. Dokiya, J. Electrochem. Soc. 150 (2003) (7) A952.

[60] I.R. Gibson, J.T.S. Irvine, J. Mater. Chem. 6 (1996) 895.

[61] D. Marrocchelli, S.R. Bishop, H.L. Tuller, G.W. Watson, B. Yildiz, PCCP 14 (2012) (35) 12070.

[62] P. Gao, E. Lara-Curzio, R. Trejo, M. Radovic, J. Electrochem. Soc. 162 (2015) (1) F14.

[63] M. Radovic, E. Lara-Curzio, R. Trejo, B. Armstrong, C. Walls, Elastic properties, equibiaxial strength and fracture toughness of $8 \mathrm{~mol} \% \mathrm{YSZ}$ electrolyte for SOFC, In:

L.H.T.a.K. W.M., Editor, 28th Cocoa Beach Conference on Advanced Ceramics and Composites Ceramics (2005).

[64] Q. Fang, T. Liu, C. Li, X. Wang, G. Zhang, Key Eng. Mater. 319 (2006) ( ) 167.

[65] M. Weller, J Alloy Compd 211-212 (1994) (0) 66.

[66] A. Lakki, R. Herzog, M. Weller, H. Shubert, C. Reetz, O. Gorke, M. Kilo, G. Borshardt, J. Eur. Ceram. Soc. 20 (2000) 285.

[67] M. Yashima, M. Kakihana, M. Yoshimura, Solid State Ionics 86-88, Part 2 (1996) (0) 1131.

[68] M.G. Cain, M.H. Lewis, M. Backshall, S.M. Bennington, S. Hull, MRS Proceedings 376 (1994) 615.

[69] J. Cai, C. Raptis, Y.S. Raptis, E. Anastassakis, Phys Rev B 51 (1995) (1) 201.

[70] S. Lukich, C. Carpenter, N. Orlovskaya, Journal of Power Sources 195 (2010) (8) 2301.

[71] A. Selçuk, A. Atkinson, J. Eur. Ceram. Soc. 17 (1997) (12) 1523.

[72] M.P. Anderson, A.S. Nowick, Journal de physique. Colloque 42 (1981) (C5) C5.

[73] K. Matsushita, Journal of Alloys and Compounds, 211/212 (1994) 374.

[74] R. Gerhardtanderson, F. Zamaninoor, A.S. Nowick, C.R.A. Catlow, A.N. Cormack, Solid State Ionics 9-10 (1983) 931. 
Table 1. Grain sizes and coefficients of thermal expansions obtained from XRD and TMA results for different $\mathrm{SOFC}$ electrolyte materials.

Figure 1. The SEM images of (a) 8YSZ, (c) SCSZ, (e) 20GDC and the optical microscopy images of (b) 8YSZ, (d) SCSZ, (f) 20GDC after thermal etching.

Figure 2. The high temperature XRD results of (a) 8YSZ, (b) SCSZ, (c) magnified results for $\mathrm{SCSZ}$ in $28^{\circ}-32^{\circ} 2 \theta$ range and (d) 20GDC. 4

Figure 3. The lattice parameter changes of 8YSZ, 10YSZ, SCSZ, 10GDC and 20GDC vs. temperature. The open symbols represent lattice parameters at $30{ }^{\circ} \mathrm{C}$ obtained after heating process.

Figure 4. The thermal expansion vs. temperature of (a) 8YSZ and 10YSZ, (c) SCSZ, (e) 10GDC and 20GDC, and instantaneous CTE vs. temperature plots for (b) 8YSZ and 10YSZ, (d) SCSZ, (f) 10GDC and 20GDC. Error bars in (b), (d) and (f) represent standard deviations from measurements in three heating and three cooling cycles

Figure 5. The typical but selected RUS resonant peaks at different temperatures for (a) 20GDC, (b) $8 \mathrm{YSZ}$ and (c) $\mathrm{Al}_{2} \mathrm{O}_{3}$. 7

Figure 6. (a) The Young's modulus and (b) shear modulus of $\mathrm{Al}_{2} \mathrm{O}_{3}, 8 \mathrm{YSZ}, 10 \mathrm{YSZ}$, SCSZ, 10GDC and 20GDC determined by RUS. 8

Figure 7. The comparison of the normalized Young's modulus of 8YSZ, 10YSZ and SCSZ obtained by RUS and DMA.

Figure 8. The comparison of mechanical damping in 8YSZ, 10YSZ, 10GDC and 20GDC by RUS. The mechanical damping of $\mathrm{Al}_{2} \mathrm{O}_{3}$ is also shown for comparison. 
Table 1. Grain sizes and coefficients of thermal expansions obtained from XRD and TMA results for different SOFC electrolyte materials.

\begin{tabular}{|c|c|c|c|}
\hline \multirow[t]{2}{*}{ Sample } & Grain size & $\begin{array}{l}\text { CTE from XRD } \\
\left(30 \text { to } 800{ }^{\circ} \mathrm{C}\right)\end{array}$ & $\begin{array}{c}\text { Average CTE form TMA } \\
\left(30 \text { to } 900{ }^{\circ} \mathrm{C}\right)\end{array}$ \\
\hline & $\mu \mathrm{m}$ & $1{ }^{\circ} \mathrm{C}$ & $/{ }^{\circ} \mathrm{C}$ \\
\hline 8YSZ & $4.93 \pm 1.60$ & $10.51 \times 10^{-6}$ & $10.31 \times 10^{-6}$ \\
\hline 10YSZ & $5.02 \pm 1.62$ & $10.56 \times 10^{-6}$ & $10.38 \times 10^{-6}$ \\
\hline SCSZ* $^{*}$ & $4.85 \pm 1.40$ & $10.33 \times 10^{-6}$ & $10.52 \times 10^{-6}$ \\
\hline 10GDC & $5.17 \pm 1.53$ & $12.00 \times 10^{-6}$ & $12.09 \times 10^{-6}$ \\
\hline 20GDC & $5.24 \pm 1.48$ & $12.22 \times 10^{-6}$ & $12.22 \times 10^{-6}$ \\
\hline
\end{tabular}

*only for cubic phase 


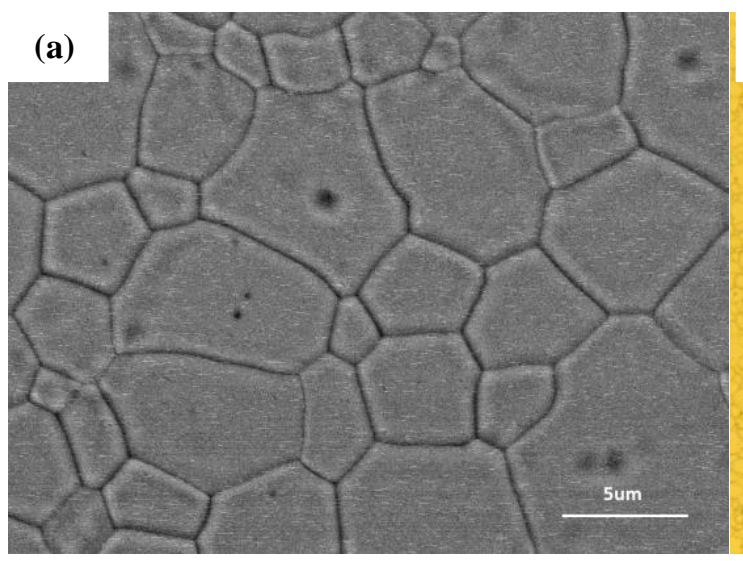

(b)

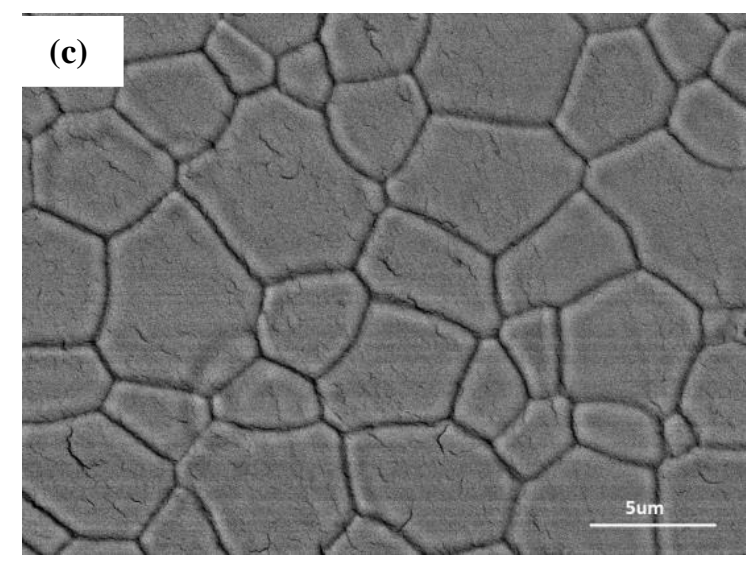

(d)

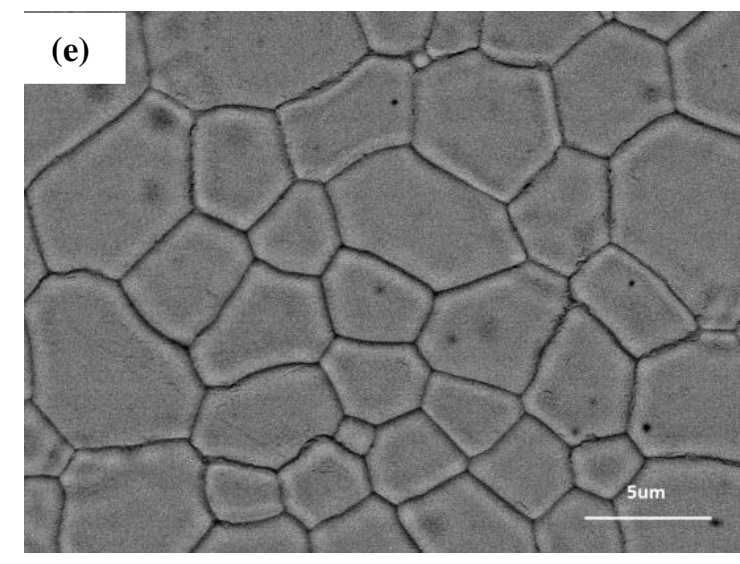

(f)

Figure 1. The SEM images of (a) 8YSZ, (c) SCSZ, (e) 20GDC and the optical microscopy images of (b) 8YSZ, (d) SCSZ, (f) 20GDC after thermal etching. 

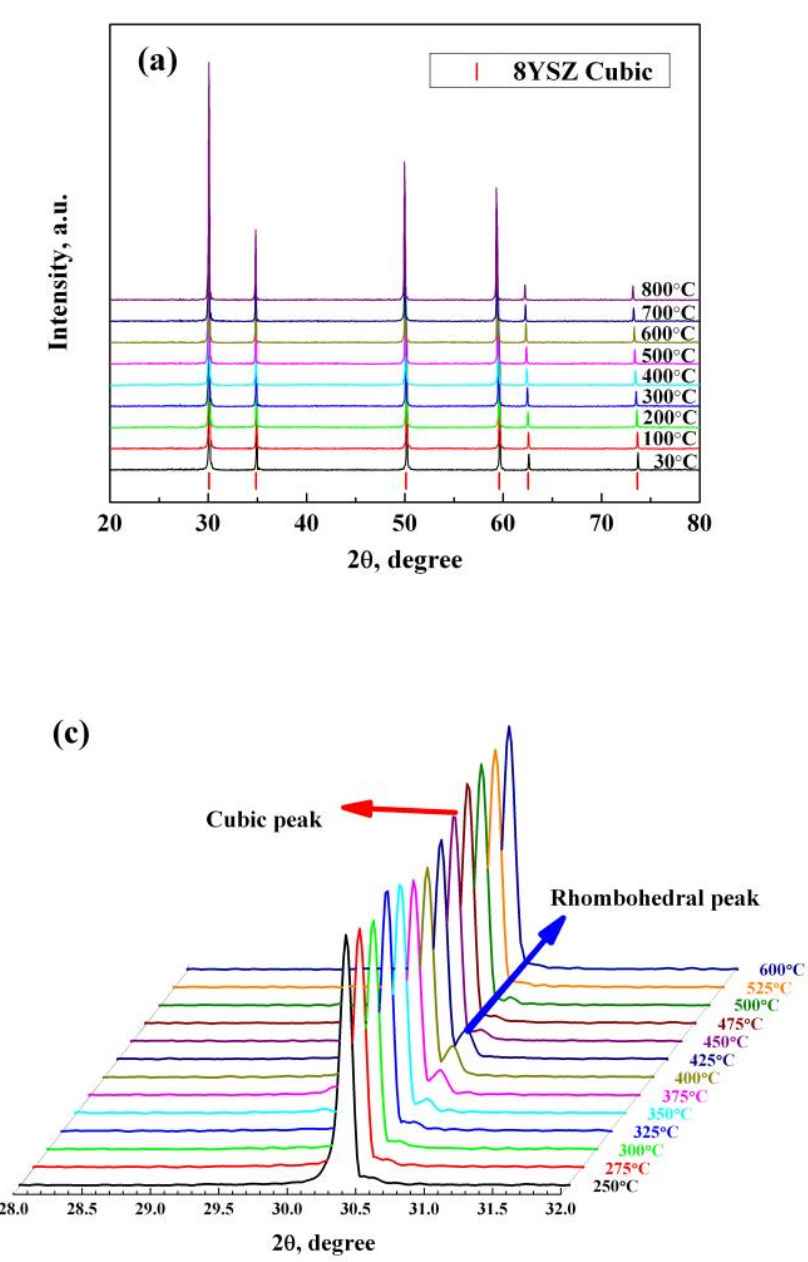
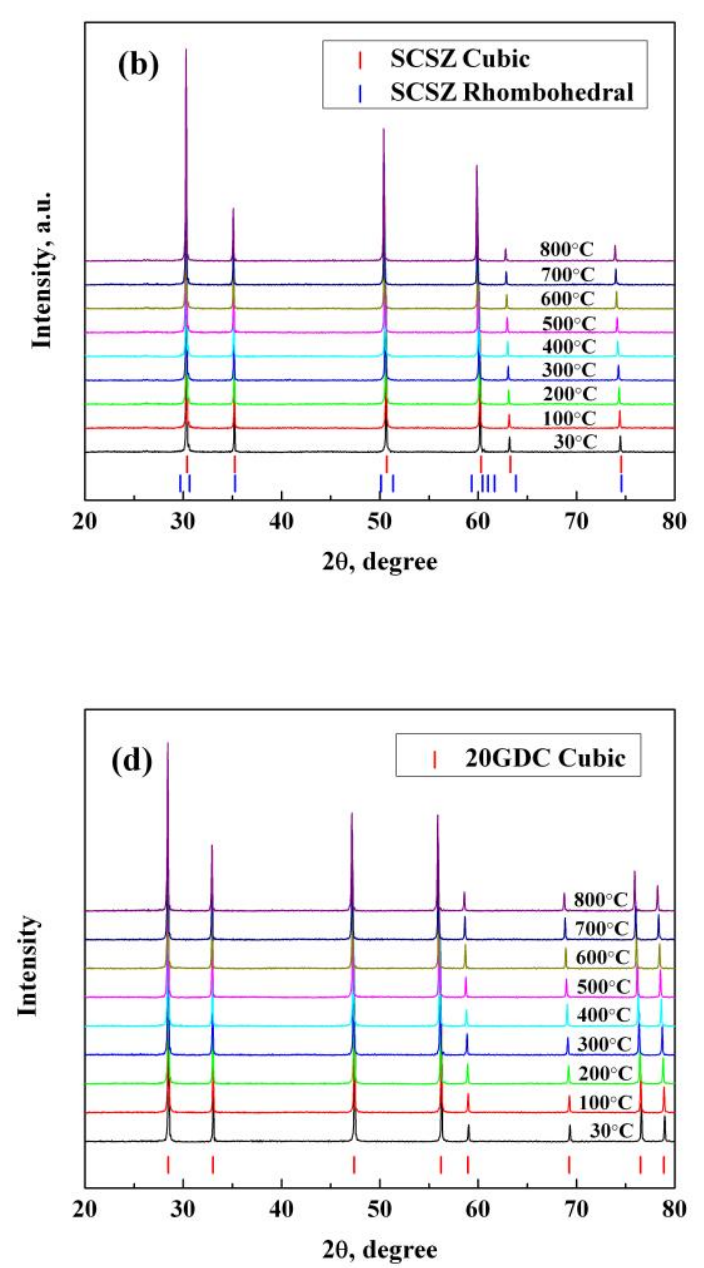

Figure 2. The high temperature XRD results of (a) 8YSZ, (b) SCSZ, (c) magnified results for SCSZ in $28^{\circ}-32^{\circ} 2 \theta$ range and (d) 20GDC. 


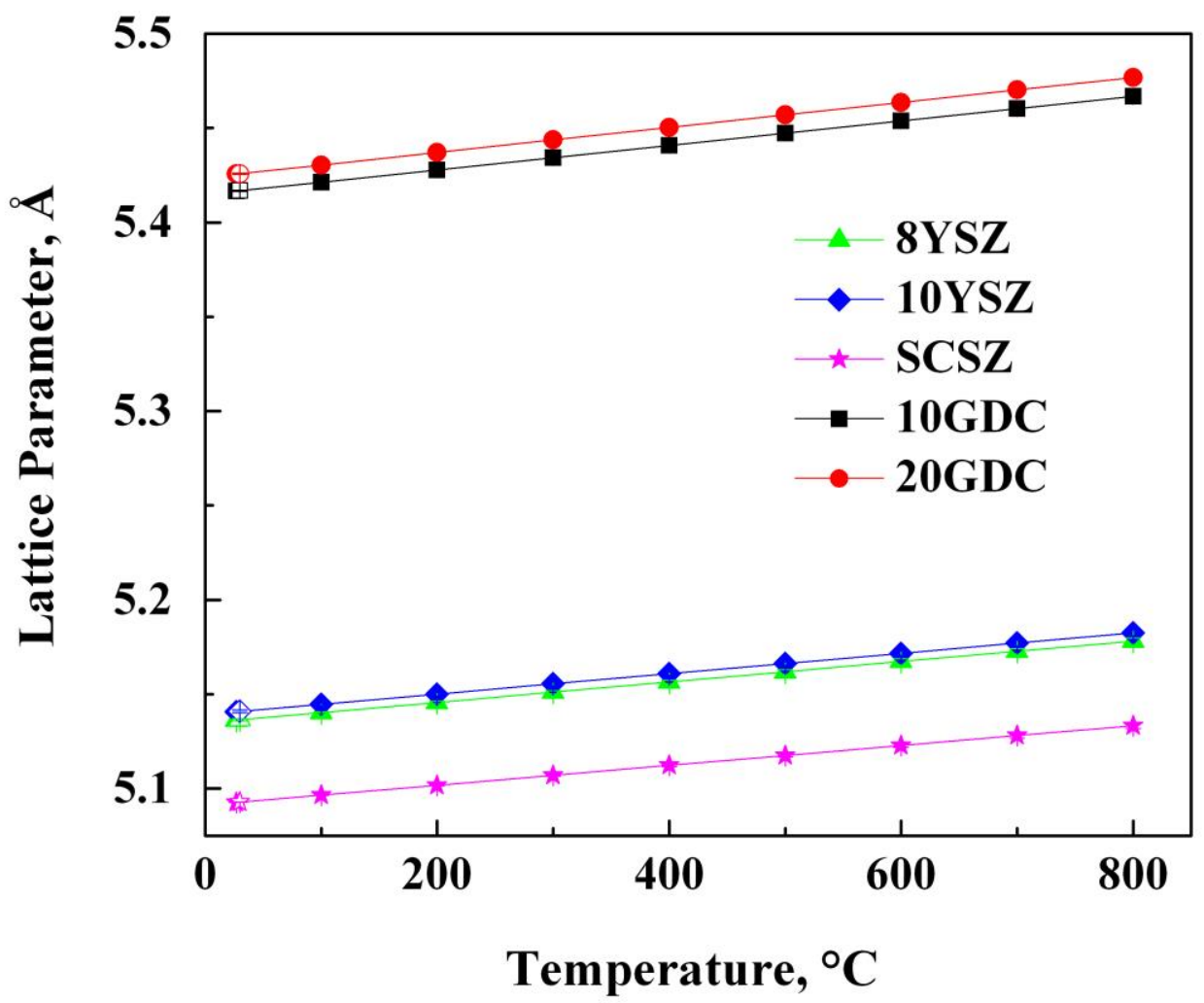

Figure 3. The lattice parameter changes of 8YSZ, 10YSZ, SCSZ, 10GDC and $20 \mathrm{GDC}$ vs. temperature. The open symbols represent lattice parameters at $30{ }^{\circ} \mathrm{C}$ obtained after heating process. 

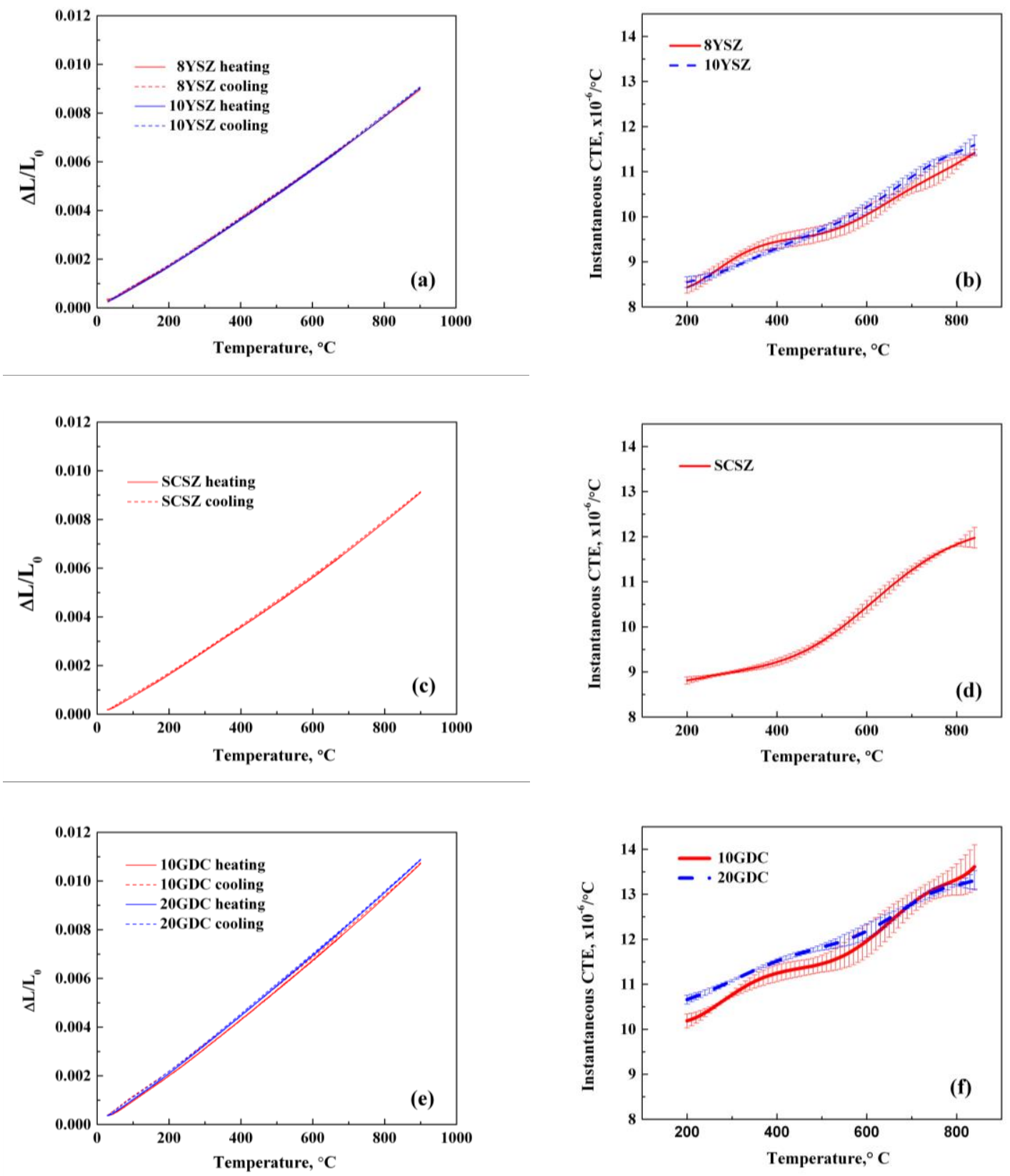

Figure 4. The thermal expansion vs. temperature of (a) 8YSZ and 10YSZ, (c) SCSZ, (e) 10GDC and 20GDC, and instantaneous CTE vs. temperature plots for (b) 8YSZ and 10YSZ, (d) SCSZ, (f) 10GDC and 20GDC. Error bars in (b), (d) and (f) represent standard deviations from measurements in three heating and three cooling cycles. 

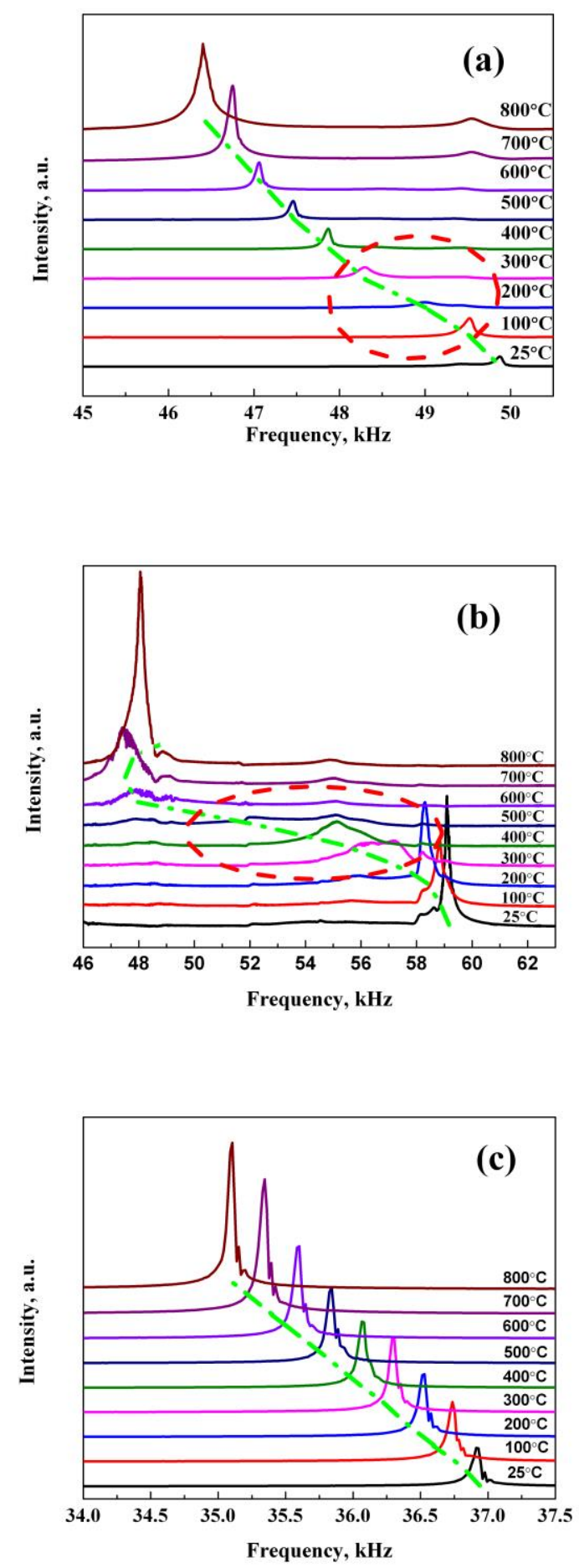

Figure 5. The typical but selected RUS resonant peaks at different temperatures for (a) 20GDC, (b) $8 \mathrm{YSZ}$ and (c) $\mathrm{Al}_{2} \mathrm{O}_{3}$. 

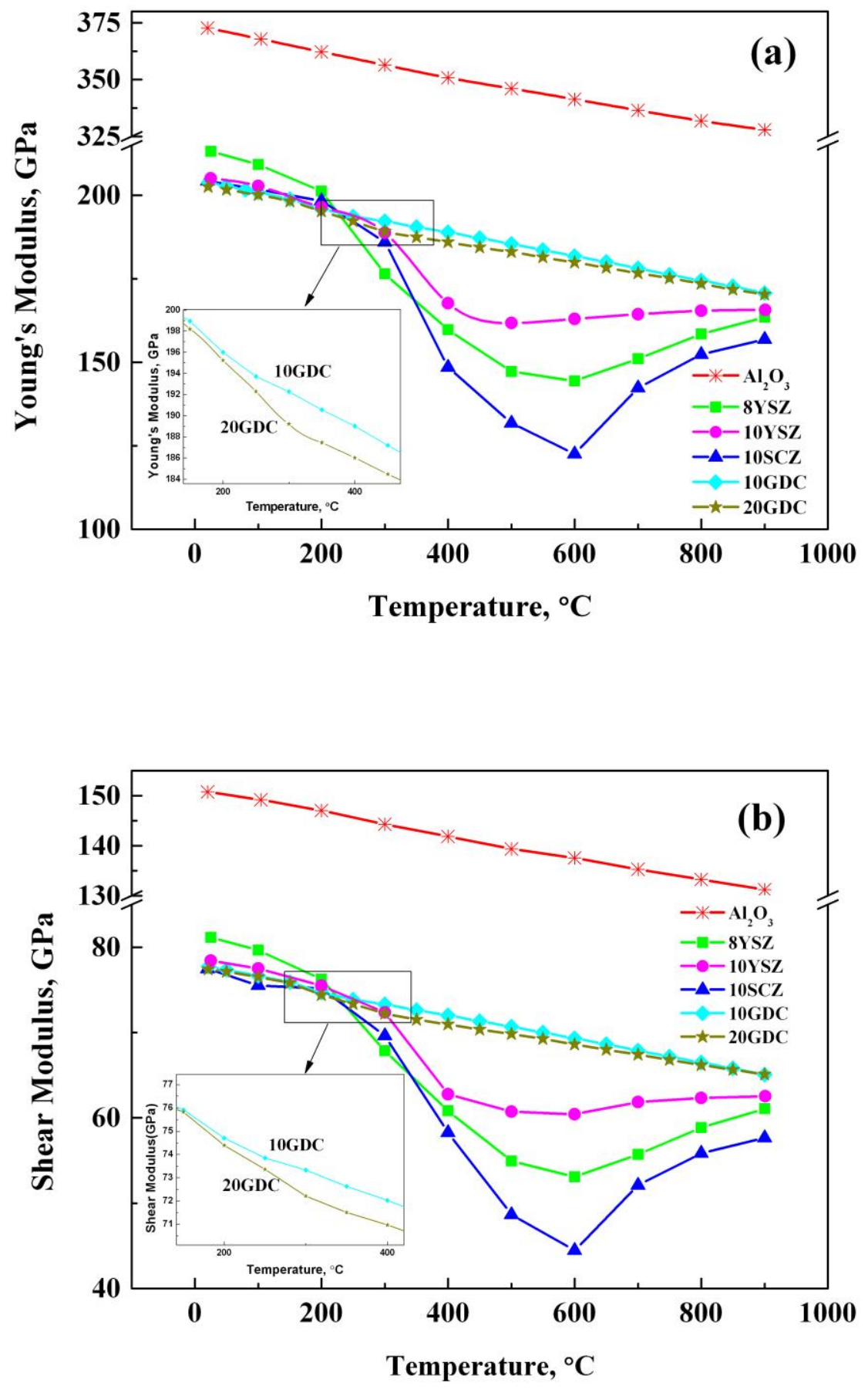

Figure 6. (a) The Young's modulus and (b) shear modulus of $\mathrm{Al}_{2} \mathrm{O}_{3}, 8 \mathrm{YSZ}, 10 \mathrm{YSZ}$, SCSZ, 10GDC and 20GDC determined by RUS. 


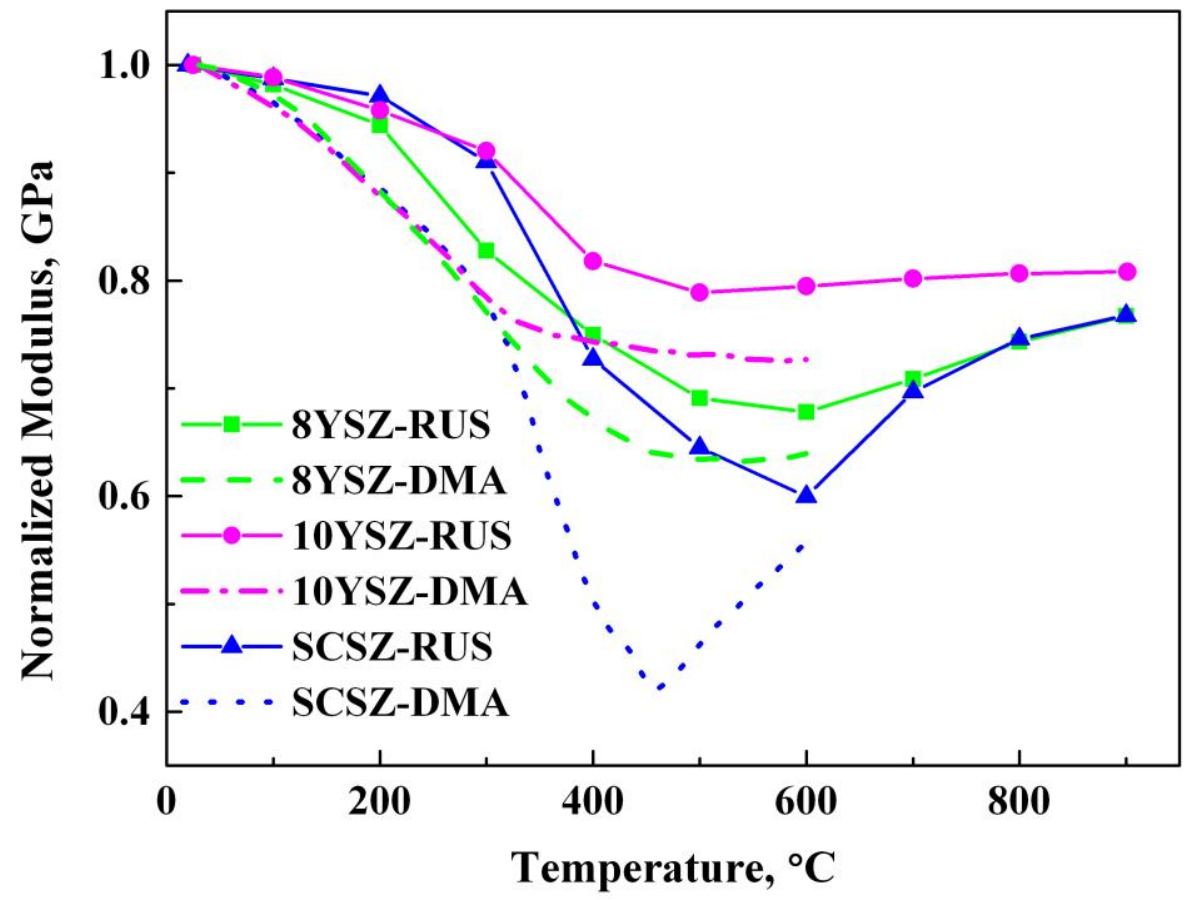

Figure 7. The comparison of the normalized Young's modulus of 8YSZ, 10YSZ and SCSZ obtained by RUS and DMA. 


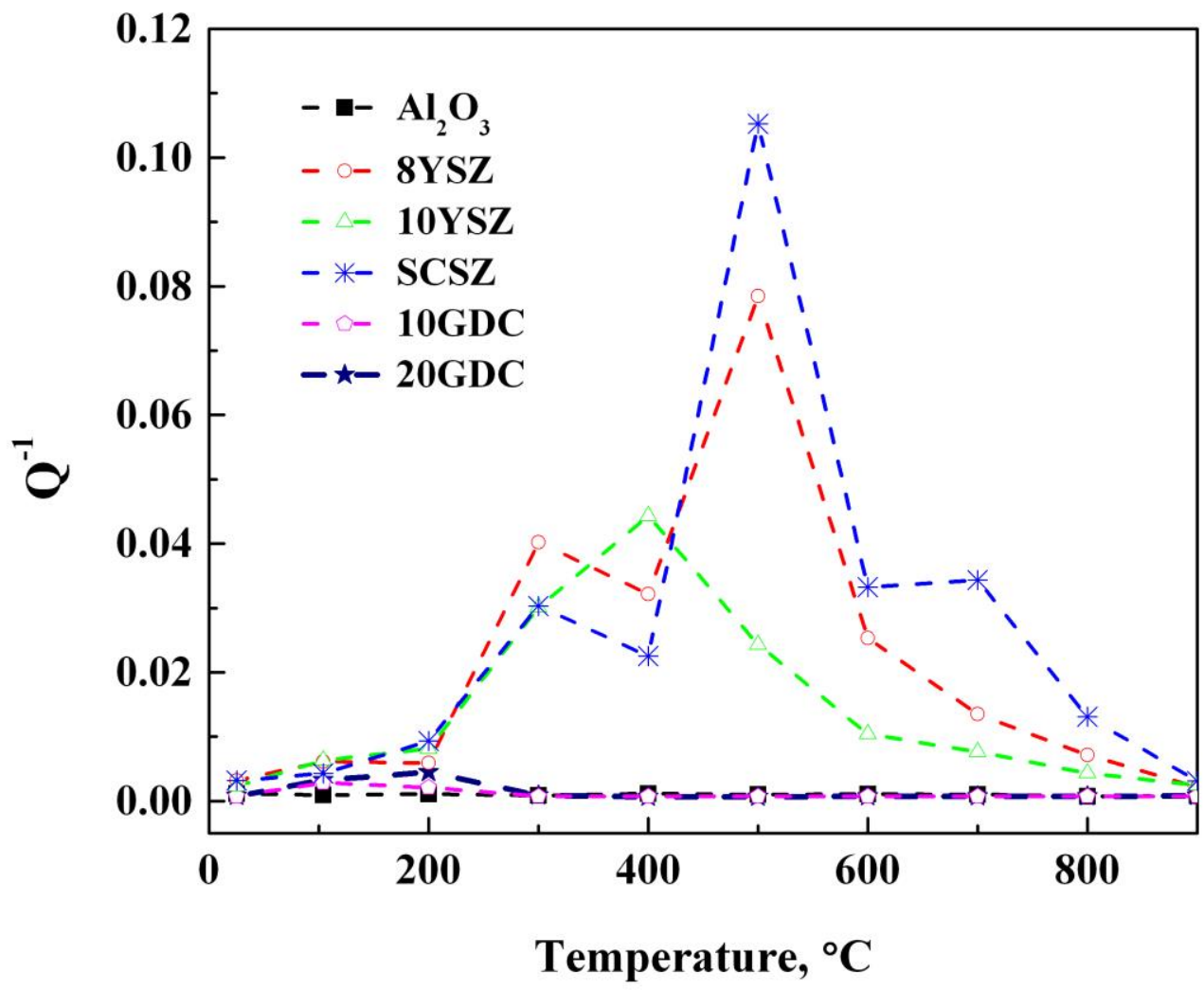

Figure 8. The comparison of mechanical damping in $8 \mathrm{YSZ}, 10 \mathrm{YSZ}, 10 \mathrm{GDC}$ and 20GDC by RUS. The mechanical damping of $\mathrm{Al}_{2} \mathrm{O}_{3}$ is also shown for comparison. 